\title{
Systematic review and meta-analysis assessing the knowledge and use of the female condom among Nigerians
}

\author{
Philemon Dauda Shallie ${ }^{1,2}$, Firoza Haffejee ${ }^{1}$
}

1. Department of Basic Medical Sciences, Durban University of Technology, KwaZulu-Natal, South Africa.

2. Department of Anatomy, Olabisi Onabanjo University, Ogun State, Nigeria.

\begin{abstract}
Background: The female condom (FC) is a critical component in a comprehensive and sustainable approach to prevent HIV, other sexually transmitted infections and unintended pregnancies.

Objectives: This review provides comprehensive information about Nigerian's knowledge and use of FC.

Methods: We screened search output, evaluated study eligibility, and extracted data in duplicate. Data from similar studies were combined in a meta-analysis.

Results: There was a significantly $(\mathrm{p}<0.0001)$ high-level of awareness amongst the respondents. However, the use of the FC was very low at 5.5\% among female respondents. There was a significant $(\mathrm{p}<0.0001)$ difference between FC awareness and use. The main reasons for FC use were prevention of unintended pregnancy $(55 \%)$ and STIs/HIV (31\%). We observed a significant difference between reasons of non-use of the $\mathrm{FC}[\mathrm{F}(5,13)=5.195, \mathrm{P}=0.0077]$. Furthermore, there were significant differences between the sources of information on FC $[\mathrm{F}(3,8)=32.89, \mathrm{P}<0.0001]$.

Conclusion: Despite the high levels of awareness, especially among the female respondents, the use of the FC has remained extremely low even among the young, educated undergraduate students. There is aneed for robust and consistent advocacy to make the FC available and affordable.

Keywords: Female condom; women; men; awareness; use; Nigeria.

DOI: https://dx.doi.org/10.4314/ahs.v21i3.48

Cite as: Shallie PD, Haffejee F. Systematic review and meta-analysis assessing the knowledge and use of the female condom among Nigerians. Afri Health Sci. 2021;21(3 ). 1362-1374. https:/ / dx.doi.org/10.4314/abs.v21i3.48
\end{abstract}

\section{Introduction}

Global surveys by United Nations in 2019 showed that globally of the 1.1 billion women who want to avoid pregnancy, $10 \%$ do not use contraceptives ${ }^{1}$. Over the last two decades there has been a change in the type of contraceptive methods used. For instance, the global prevalence of female sterilisation has declined from 13.7 per cent in 1994 to 11.5 per cent in 2019. Although, the use of the pill, IUD and rhythm methods have remained relatively stable over the past 25 years, the use of male condoms have more than doubled worldwide from $4.5 \%$ in 1994 to $10.0 \%$ in 2019 . In sub-Saharan African countries, the prevalence of implants (Levo-

\section{Corresponding author:}

Philemon Dauda Shallie,

Department of Basic Medical Sciences,

Durban University of Technology,

KwaZulu-Natal, South Africa.

Tel. No: +27710214171, +2347033971642

Email address: shallie.philemon@gmail.com norgestrel and Etonogestrel), injectable contraceptives and male condoms has increased ${ }^{1}$.

The pill and the barrier contraceptives have their own unique advantages and disadvantages; condoms offer far more protection against STDs than hormonal forms of birth control, which offer no protection against sexually transmitted disease (STD) at all, however the pill is slightly more effective at preventing pregnancy than condoms. They also have several complementary benefits; using condoms and the pill simultaneously further lowers the risk of pregnancy while offering protection against most STDs, making them a good combination when used together. Nevertheless, condoms have a range of advantages over other forms of birth control, from their low cost to their ability to prevent the spread of most STDs ${ }^{2}$.

Despite the reported gradual decline in the HIV epidemic, it has remained a cause of great concern for developing countries in sub-Saharan Africa, where twothirds of all infected persons live, and three-quarters of global deaths occur ${ }^{3,4}$. The current Nigerian national HIV prevalence among adults aged 15-49 years is 
1.9 million people $(1.4 \%)$, this is more than twice in females $(1.9 \%)$ than in males $(0.9 \%)$. Younger women aged 20-24 are more than three times likely to be living with HIV than younger men of the same age group. The prevalence varies across the geopolitical regions; South-South (3.1\%), North-Central (2.0\%), SouthEast $(1.9 \%)$, South-West (1.1), North-East (1.1\%), and North- West $(0.6 \%)^{5}$. It was also stated that the prevalence of STDs among young Nigerian females is $17 \%$ and that these increase the risk of both female infertility as well as transmission of HIV/AIDS ${ }^{6}$. Furthermore, adolescent pregnancy is a daunting problem in Nigeria. Studies have shown the prevalence of unintended pregnancy among adolescents range between $23 \%$ and $36 \%$ in the different regions of the country ${ }^{6}$.

The global effort to curb the spread of HIV and other sexually transmitted infections (STIs), has resulted in the introduction of condoms ${ }^{7}$. These are a significant component in a comprehensive and sustainable approach to prevent HIV and other sexually transmitted infections (STIs) and are effective in preventing unintended pregnancies ${ }^{8}$. The female condom (FC) was introduced as a female-initiated protective barrier that prevented pregnancy and HIV as well as other STIs and its uptake was regarded as safe ${ }^{7,9}$. Although, the FC sought to provide women with the ability to have a controlled decision of sexual protection, its use is not entirely female-controlled, as a woman needs the co-operation of her male partner ${ }^{9}$. Nigerian Demographic and Health Surveys (DHS) 2008, statistics showed that although $14.7 \%$ of all women had heard about the FC and $13.9 \%$ had heard a specific family planning message on the FC, only $0.2 \%$ had ever used one ${ }^{10,11}$. The promotion of the FC remains important, despite both successes and disappointments, especially in the face of heterosexually acquired HIV infection rates that are soaring globally ${ }^{\text {? }}$.

In the baseline study conducted in 2011 by the Society for Family Health (SFH), Nigeria, 38.9\% of respondents had heard about FCs, but only 3.5\% of these had ever used one. Thus $1.4 \%$ of all respondents had ever used an FC and $1.7 \%$ of the male respondents reported that their female sex partners used FC compared to $1.0 \%$ among the female respondents ${ }^{11}$. Most youths in Nigeria and elsewhere are sexually active and engage in risky sexual behaviours, such as early sexual debut, unprotected sex, multiple sexual partnerships and anal sex. In addition, they have incorrect knowledge of STIs ${ }^{12-14}$. Furthermore, they lack the confidence to negotiate sex or contraceptive use. At the same time, many do not perceive themselves as being at risk of contracting STIs, including HIV and AIDS ${ }^{14-16}$.

Correct and consistent use of condoms, including the FC, is one of the best ways to prevent STIs, including HIV and AIDS ${ }^{17}$. Some national and international agencies like Universal Access to FCs (UAFC), have set out objectives to increase public awareness to create FC demand and ensure availability of FCs in order to reduce the number of unintended pregnancies and subsequently reduce maternal deaths, as well as to reduce the preponderance of HIV and sexually transmitted infections (STIs) ${ }^{11}$.

This review provides comprehensive and current information about the knowledge and use of FC among Nigerians of reproductive age, in order to stimulate research interest geared to address the existing FC programs and to enhance its acceptance and use in the country.

\section{Methodology}

The preferred reporting items for systematic reviews and meta-analysis (PRISMA) model was used to develop the review process ${ }^{18}$. We searched the literature in two databases: Google Scholar and PubMed for literature and earlier reviews. Screening titles and abstracts for combinations of the terms "female condom," "use among women in Nigeria," and "male perception." In order not to miss out on publications, we included words in our search terms that might indicate acceptability or its opposite, such as accept(ance), adopt(ion), attitude (attitudinal). A total of 117,000 search hits were generated, which was scaled down to 11,400 when the search was limited to Africa and subsequently scaled down to 2,805 when the search was limited to Nigeria. From these, 51 published articles and reviews were carefully examined and filtered by the authors. Of these, only 17 studies met the inclusion criteria for the study (see Fig. 1). The search mode used was the Boolean search. The following search terms were used to filter the required studies: "condom use," "Nigeria," "woman or female or girls," and "female condom".

\section{Inclusion and exclusion criteria}

We searched literature published between 2000 and 2020, with the following eligibility criteria: (1) published in the English language and comprised of either quantitative or qualitative research design; (2) retrievable, as a full study, a review, or as an article in peer-reviewed scientific journals; (3) have a sound scientific methodology; (4) study female knowledge, acceptability, attitude or perception of use of the FC; (5) report on wom- 
en in Nigeria and (6) studies with both male and female perspectives where each perspective was reported separately and could be extracted from the studies. We found 51 studies, 17 of which met and 34 did not meet all pre-set criteria.

The exclusion criteria ranged from dual country comparative studies, which were excluded due to cross-tabulation of results and mixed-gender studies, where the female perspective could not be extracted. Seventeen eligible studies were subjected to an in-depth analysis.

The following information was extracted from the articles: author names, year of publication, study population, study design, sample size, outcome measures, and results. Studies are presented in chronological order in Table 1. Outcome measures that were common in the studies were identified and used to create themes to understand Nigerian women's current awareness and FC use.

\section{Patient and Public Involvement (PPI) statements}

This systemic review was done without patient involvement. Patients were not invited to comment on the study design and were not consulted in the development of relevant outcomes or the interpretation of the results. Patients were not invited to contribute to the writing or editing of this document for readability or accuracy.

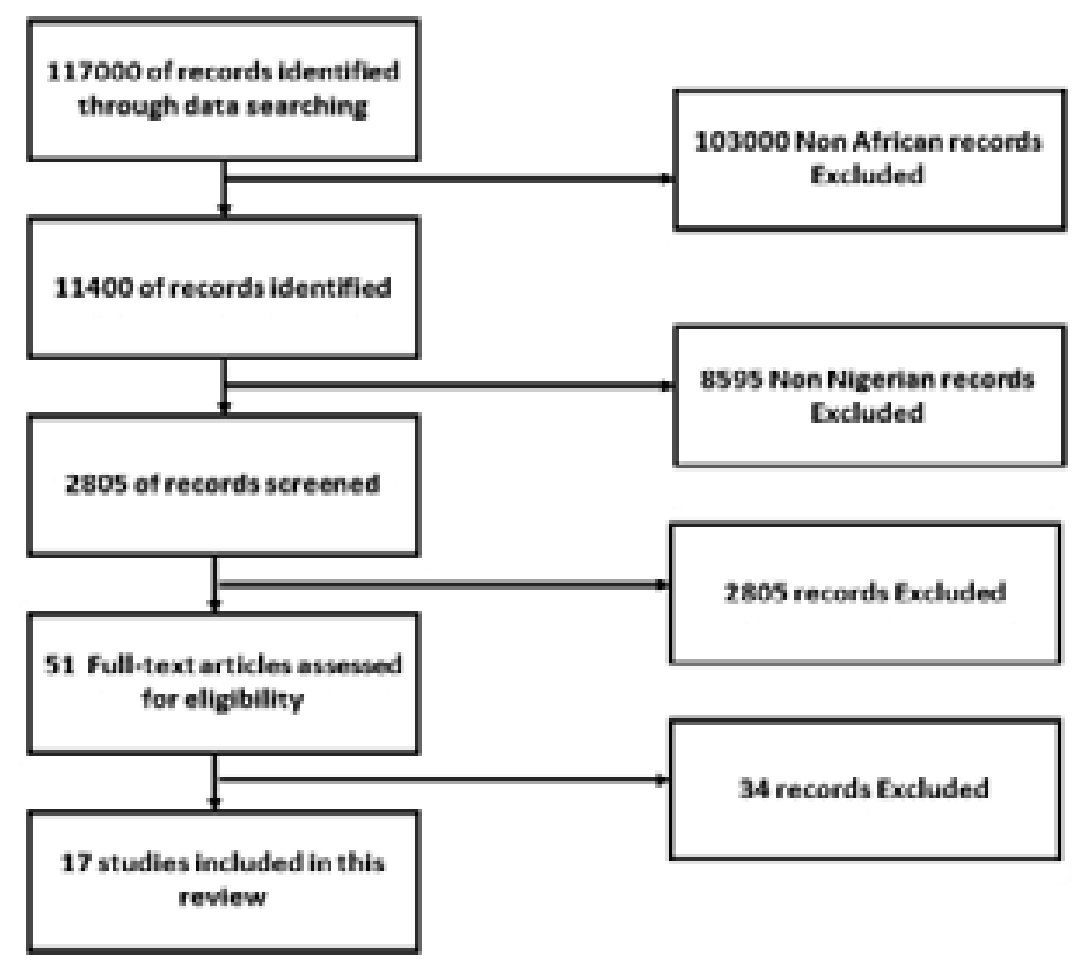

Fig. 1: Flow Diagram of Literature Selection

\section{Results}

Figure 1 summarises the search and selection process. We generated 117,000 search hits, which were scaled down to 11,400 when the search was limited to Africa and subsequently scaled down to 2,805 when the search was limited to Nigeria. The authors carefully examined and filtered 51 published articles and reviews. Of these, only 17 studies met the inclusion criteria for the study. The authors analyzed one retrospective review, two retrospective surveys, thirteen cross-sectional studies, and one qualitative study. Common themes from the outcome assessments of each study were derived and are explained in detail below. These themes are summarized and compared in the chronological lists in Tables $1 \mathrm{a}$ and $1 \mathrm{~b}$. 
Table 1a: Summary of Studies Investigating Female Condom (FC) Use among Nigerian Women.

\begin{tabular}{|c|c|c|c|c|c|c|}
\hline $\begin{array}{l}\text { Study } \\
\text { No. } \\
\end{array}$ & $\begin{array}{l}\text { Authors/ } \\
\text { Year }\end{array}$ & Study Design & sample size & $\begin{array}{l}\text { Study } \\
\text { Duration }\end{array}$ & Outcome Assessment & Results \\
\hline 1 & $\begin{array}{l}\text { Uchendu, O. C., } \\
\text { Adeyera, O., \& } \\
\text { Owoaje, E. T. (2019) }\end{array}$ & $\begin{array}{l}\text { Cross } \\
\text { sectional } \\
\text { study }\end{array}$ & $\begin{array}{l}964 \\
674-\mathrm{M} \\
290-\mathrm{F}\end{array}$ & $\begin{array}{l}\text { Not } \\
\text { specified }\end{array}$ & $\begin{array}{l}\text { Awareness and } \\
\text { utilization } \\
\text { of FC predictors } \\
\text { of FC awareness and } \\
\text { utilization. }\end{array}$ & $\begin{array}{l}\text { Almost half } 47.9 \% \text { of the respondents } \\
\text { have heard about the FC however only } \\
16.8 \% \text { have ever seen one while } 4.3 \% \\
\text { have ever used an FC. Age, education, } \\
\text { current sexual activity and experience of } \\
\text { rape attempt were predictors } \\
\text { of FC awareness. }\end{array}$ \\
\hline 2 & $\begin{array}{l}\text { Adinma, J., Adinma, } \\
\text { E., Eke, N., \& } \\
\text { Umeononihu, O. } \\
(2016) .\end{array}$ & $\begin{array}{l}\text { Cross } \\
\text { sectional } \\
\text { study }\end{array}$ & $\begin{array}{l}276 \\
168-\mathrm{M} \\
108-\mathrm{M}\end{array}$ & $\begin{array}{l}\text { Not } \\
\text { specified }\end{array}$ & $\begin{array}{l}\text { Awareness and use } \\
\text { of FC; reasons for non- } \\
\text { use of FC; indication } \\
\text { for FC use; awareness of } \\
\text { functions } \\
\text { of FC knowledge of the } \\
\text { pitfalls of FC; and source } \\
\text { of information of FC. }\end{array}$ & $\begin{array}{l}\text { About } 62.3 \% \text { were aware of FC. } 5.1 \% \\
\text { respondents have ever used } \\
\text { the FC. Reason for non-use of FC } \\
\text { were religious belief } 3.3 \% \text {, not knowing } \\
\text { how to use FC } 20.5 \% \text { and preference for } \\
\text { other methods of contraception. } 7.7 \% \text {. } \\
\text { Lack of money was the reason for non- } \\
\text { use by } 5.1 \% \text { respondents. Many of the } \\
\text { respondents } 50.5 \% \text { used FC when afraid } \\
\text { of STI or pregnancy. However, few } \\
\text { others used it only during sex with a } \\
\text { non-regular partner } 22.1 \% \text { and only } \\
\text { when requested by partner } 12.6 \% \text {. }\end{array}$ \\
\hline
\end{tabular}

Usman, S. O.,

Kalejaye, O. O.

Isola, I. N.,

Oluwaniyi, O.,

Ojogbede, A. K., \&

Adu, A. S. (2016)

Ajayi, A. I., Adeniyi,

O. V., \& Akpan, W.

(2018).

Cross

sectional

study

Cross

sectional

study

Ijarotimi, A. O.,

Bakare, B.,

Badejoko, O. O.,

Fehintola, A. O.,

Loto, O. M., Orji, E.

O., \& Adegoke, A. S.

(2017).

-survey
Ikeako, L., Ezegwui, H., Mba, S., Iyioke,

C., \& Okeke, T. (2015).
1500

Retrospective

Cross

sectional

study
May-

Sept 2016

FC use, reasons for use and source of information.

Knowledge of contraception, use of contraception and reasons for non-use of contraception.

2004-2009 FC use
FC use is $2.9 \%$ some of the respondents believe that contraception prevents unwanted pregnancy $62.0 \%$ and limits family size $58.9 \%$. Their source of information was mainly through health personnel in the government-owned hospitals $(50.1 \%)$.

FC Awareness $-93.1 \%$, ever use- $0.2 \%$ out of 645 currently using $0.2 \%$ out of 538. Reasons for non-use of FC are fear of side effects and non-availability.

FC use was $0.8 \%$.
FC awareness was $76.7 \%$ and $15.9 \%$ had used it, with most acquiring information about the device from their friends $43.8 \%$, media $40.4 \%$, health workers $23.3 \%$ and sex partners $7.5 \% .12 \%$ used it to prevent pregnancy only, $20 \%$ used it to prevent sexually transmitted infections only while $38 \%$ used it to prevent both unwanted pregnancy and sexually transmitted infections including HIV/AIDS. About 28\% used female condoms just to try it. Reasons cited for non-use are decreased sexual satisfaction $30 \%$ and pain during sexual intercourse $30 \%$. Others experienced difficulty in inserting female condoms into the vagina $28 \%$, noise during sexual intercourse, $12 \%$ and failure leading to pregnancy $2 \% .54 \%$ of male partners strongly approved of it, while $14 \%$ strongly disapproved. 
Nwaokoro, J., Ede,

A., Ibe Sally, N.,

Emerole, C., Nwuto,

R., Nwaokoro, A., \&

Igwe, I. (2015).
Cross-

sectional

study
Not

specified
Knowledge of FC, knowledge of how to use of FC, source of FC knowledge.
8

9

Asekun-Olarinmoye,

E., Adebimpe, W.

Bamidele, J., Odu,

O., Asekun-

Olarinmoye, I., \&

Ojofeitimi, E. (2013).

Onyekwere, V. N., \& cross-

sectional

study

U., Ugwu, E. O.,

(2014).

Onoriode Ezire, Obi

Oluigbo, Victoria

Ifeanyi and Jennifer

Anyanti (2013)

Tobin-West, C. I.,

Maduka, $\mathrm{O}$.

Tella, A. O. (2014).
Qualitative $\quad 78$ study

cross-
sectional
study

(n)

cross-

sectional

study
400

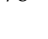

900-- 427

(52.7\%)

females and

383

(47.3\%)

males;
March 1 to FC use and reasons for August 31, non-use.
Not specified

FC use and reasons for FC use.

Knowledge, access, acceptability and use of FC, sources of information on $\mathrm{FC}$.
November

2011
Not Respondents'

specified awareness and reasons

for use of FC and male partners' consent.
2007

National

HIV/AIDS

and

Reproducti

ve Health

Survey

(NARHS)

13

Oladeinde, B. H.,

cross-

435 (261)

Omoregie, R., \&

sectional

Abdulfatai, A

study

Not

specified
Knowledge of FC, use of $\mathrm{FC}$, reasons for use and non-use, predictors of use of FC.

Knowledge and use of $\mathrm{FC}$, reasons for use or not use and sources of knowledge.
Awareness of FC was $61.4 \%$, while $25.2 \%$ said they knew how to use the FC. The students that reported that they use FC in every sexual intercourse were $3.4 \%$ it. In all, $23.6 \%$ were aware of the FC from the radio, $10.6 \%$ from television, $5.7 \%$ from books, and $6.5 \%$ from school. The largest source was from friends $(53.7 \%)$. The most quoted reasons for use of $\mathrm{FC}$ was to protect against HIV/AIDS.

Sixty-two participants (25.1\%) used a dual-contraceptive method. None of the participants reported the use of FC. The non-use of FC observed in the present study might be due to the scarcity and in some places the non-availability, of the female condom in most health facilities in South-Eastern Nigeria.

FC users are 58 out of 78 . Reasons for the use of FC were curiosity, to prevent unplanned pregnancy. FC provided the opportunity to meet the sexual needs of the partner irrespective of the woman's is menstrual cycle.

Although $89.3 \%$ were aware of FC, only $8.9 \%$ had ever used one due to unavailability, high cost, and difficulty with its insertion. Nevertheless, 53.8\% of the students expressed willingness to use them if offered, while $69.4 \%$ would recommend it to friends/peers. Information on $\mathrm{FC}$ were gotten from the media, health facilities, friends', peers and relations.

FC awareness was $65.5 \%$ aware of FC. Among the most common cited reasons for use of FC were child spacing $(63.5 \%)$ and prevention of unwanted pregnancies $(59.9 \%) .3 .6 \%$ of the male partners disapproved of it.

The women that have heard of FC were $12.6 \%$ and $5.7 \%$ knew where to get them. However, only $0.4 \%$ had ever used the female condom. Reasons for non-use were: it slipped out $0.2 \%$, made noise $0.1 \%$ dislike $0.1 \%$. The predictors of use of FC were age at first sexual intercourse.

Awareness of the FC was significantly higher among female undergraduate students (FUGS) $(93.7 \%)$ than rural resident women (RRW) $(5.2 \%$. No significant difference was observed in level of use of the FC between FUGS (1.9\%)

and RRWM ( $0 \%)$. Reasons for non-use are unavailable $5.7 \%$, ashamed to buy product $4.8 \%$, belief forbids its use 1 $\%$, partners disapproves $4.7 \%$. While the reasons for use are to prevent pregnancy $88.6 \%$ in FUGS and $55.5 \%$ in RRW, tO Prevent HIV transmission $100 \%$ in FUGS and $33.3 \%$ in RRW, to prevents STIs $75.1 \%$ in FUGS and $11.1 \%$ in RRW. Sources of knowledge includes Internet $42.0 \%$, media $86.9 \%$ and friends $15.1 \%$. 
cross-

sectional

Ojofeitimi, E. O., \& study

Adeomi, A. A.

(2010).

$\begin{array}{ll}\text { Abalaka G. (2008) } & \begin{array}{l}\text { cross- } \\ \text { sectional } \\ \text { survey }\end{array}\end{array}$

survey

16 kunlola, M.,

Morhason-Bello, I.,

Owonikoko, K., \&

Adekunle, A. (2006).

cross-

sectional

survey

retrospective
review

1355

Adeyemi, A. S.,

(2009).
Not

specified

Knowledge, use, reasons

for use and no use of

barrier contraception (B

C)

Not
specified

Awareness, knowledge, usage and reasons for use and non-use of FC.

Sources of information on FC.

Knowledge and use

Not specified the use, sources of information on FC and male partner's consent.

FC use, reasons for use and sources of 2001 and December 2006
Knowledge of FC $87.4 \%$ used the FC $0.6 \%$. Reasons for use are to prevent STI and unwanted pregnancy. Reasons for not were religion, uncertainty about safety, culture, decreased sexual pleasure, and belief.

Less than half $40.6 \%$ and $27.8 \%$ had ever heard of and seen female condom respectively. Only $4.3 \%$ of those had ever used it. Seventyone percent of those who had ever used female condom intended to continue, while $29.4 \%$ were unsure. Reasons for use are to prevent unwanted pregnancy $(80 \%)$ and prevention of STls (28.4\%). While reason for non-uses includes the fear of FC dropping into woman's body leading to death (29.7\%), its oily nature $(23.9 \%)$, the balloon-like look $(23.9 \%)$ and inhibiting natural sexual feeling $(14.2 \%)$. Information on $\mathrm{FC}$ were from health facilities $(41.3 \%)$, media at $32.3 \%, \quad 24.5 \% \quad$ respondents heard about FC from their neighbours, while $15.5 \%$ from academic institution.

Over $80 \%$ had knowledge of the $\mathrm{FC}$ as a form of contraception and the majority of them learnt about it through the mass media (39.9\%) and health workers $(34.4 \%)$. However, only $11.3 \%$ had ever used the female condom. The majority $(42.7 \%)$ of the sexual partners of female condom users approved of it; however $39.6 \%$ of sexual partners disapproved while $17.7 \%$ were indifferent. Most $(40 \%)$ using it to prevent both unwanted pregnancy and sexually transmitted infections including HIV (STI/HIV); $27.1 \%$ to prevent pregnancy alone and $19.8 \%$ to prevent STI including HIV only, while $12.5 \%$ used it on a trial basis. Reasons for not use: lack of sexual satisfaction $(30.2 \%)$. Other problems encountered included difficulty in inserting it into the vagina $(21.7 \%)$, pain during sexual intercourse $(5.2 \%)$ and method failure resulting in pregnancy in two $(2.8 \%)$ of the respondents

FC use was $0.2 \%$. Reasons for use of FC 37.8\% to prevent further pregnancy, $56.9 \%$ for child spacing and $5.6 \%$ not sure, if they want kids again. Sources of information on FC were family planning clinic personnel $76.7 \%$, media (print ad electronic) $11.2 \%$, friends and relatives $9.4 \%$ and community health workers $2.7 \%$.

Abbreviations: $\mathrm{FC}=$ female condom 
Table 1b: Summary of the outcomes assessed across the studies.

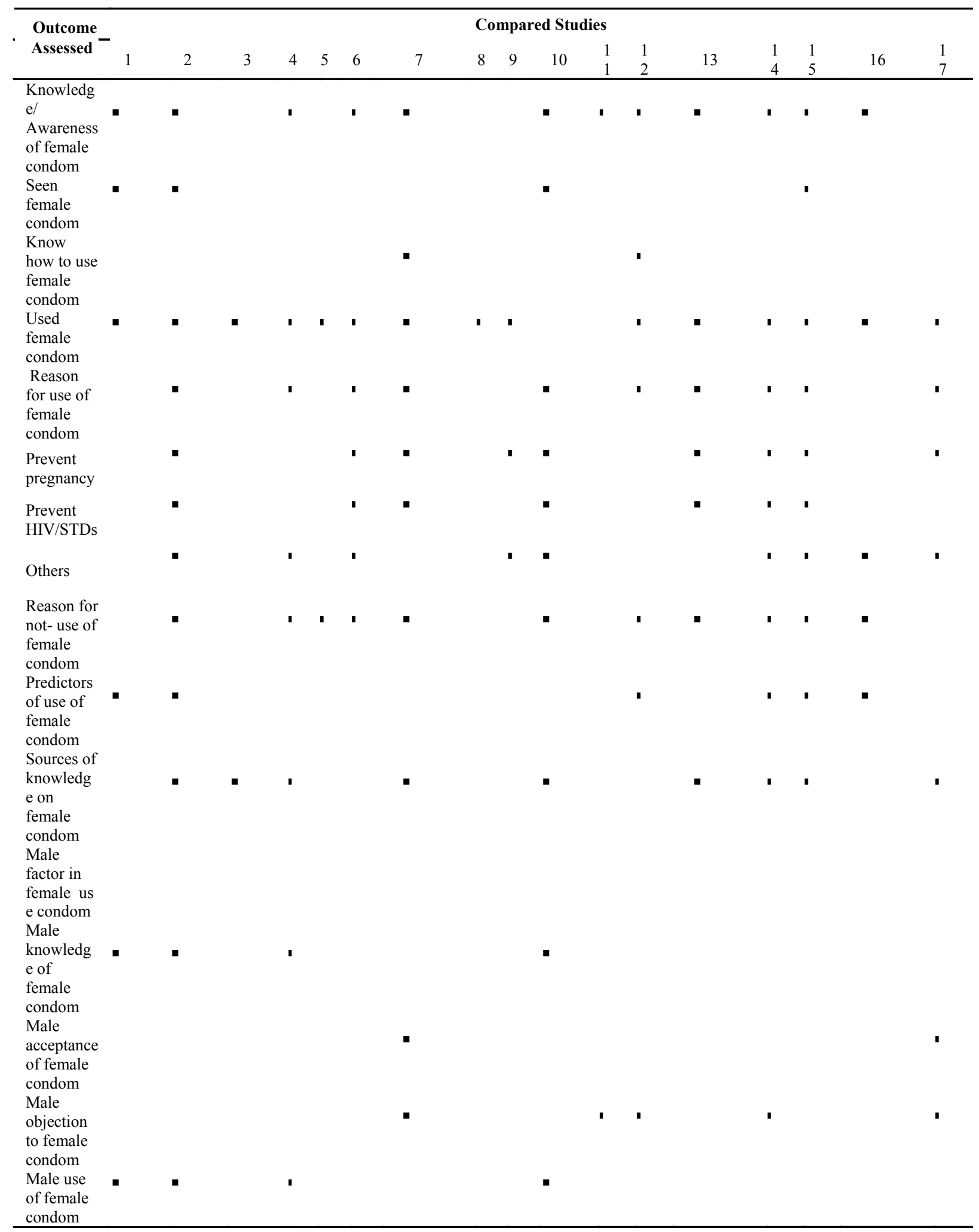

\section{Participants and Statistical Analysis}

The number of participants in each study ranged from 78 to 5,360 women. The seventeen studies included 14,949 women and 1,225 men. Graphpad Prism statistics software, version 7 (California, USA) was used to analyse the data. Descriptive statistics for continuous data is presented by mean \pm standard deviation. To determine the statistical difference between study groups and across study groups, the one-way ANOVAest was used. A p-value of $<0.05$ was considered statistically significant. 


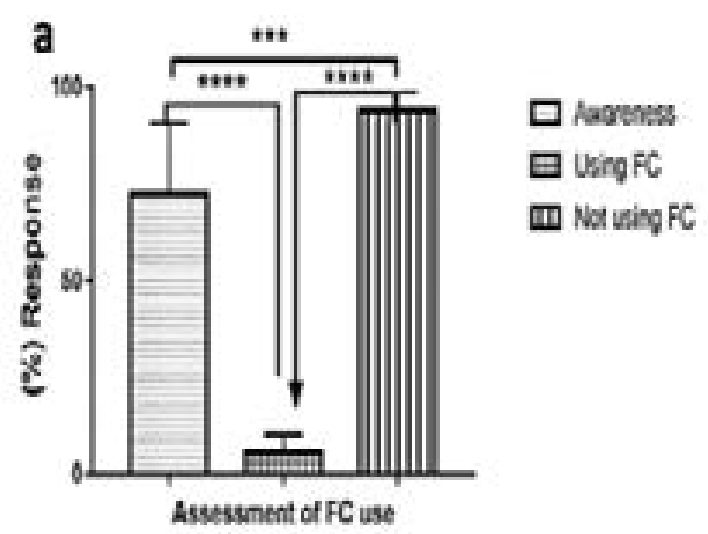

Fig. 2: Female condom awareness and use in (a) female and (b) male respondents.

\section{Female condom awareness and use}

Figures $2 \mathrm{a} \& 2 \mathrm{~b}$ present the assessments on FC use in males and females respectively. One-way ANOVA analyses showed significant differences between females $[\mathrm{F}$ $(2,27)=69.34, \mathrm{p}<0.0001]$ and males $[\mathrm{F}(2,6)=84.21$, $\mathrm{p}<0.0001]$. Significant differences were also noted in the knowledge versus FC use for females $(p<0.0001)$ and males $(\mathrm{p}<0.001)$; knowledge versus FC not used showed significant differences in both females $(\mathrm{p}<$ $0.0001)$ and in males $(\mathrm{p}<0.01)$. In addition, a significant difference $(\mathrm{p}<0.0001)$ was observed between FC use versus FC not use in both genders.

Twelve studies reported awareness or knowledge of FC, with percentage awareness ranging from 93.7\% amongst female undergraduate students 19 to $40.6 \%$ amongst married women ${ }^{20}$. In this review, after meta-analysis, we reported an average awareness of $72.5 \%$ and $46.9 \%$ amongst the female and male respondents, respectively (Fig.2). Seven of the studies were conducted amongst undergraduate students; three of which were in the South-Western region, an average awareness of $87.03 \%$ (range: $80-93.7 \%$ ) ${ }^{19,21,22}$. The South-South region followed with an average awareness of $89.3 \%$ conducted among 900 respondents made up of both males and females ${ }^{14}$. The South-Eastern region reported lowest awareness rates in the three sets of studies; $76.7 \%$, $62.3 \%$, and $61.4 \%{ }^{23-26}$, with an average of $66.8 \%$. The three studies that reported awareness among women showed a wide variation of awareness: ranging from $40.6 \%$ to $93.1 \%$ in married women ${ }^{20,27}$ and $65.5 \%$

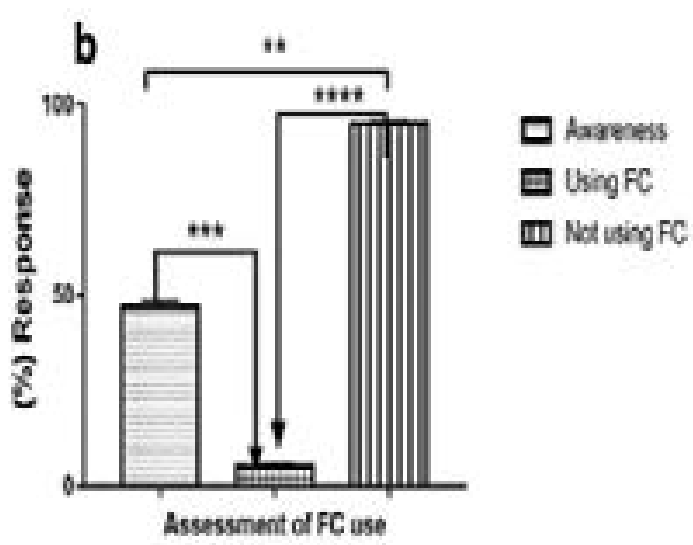

mong women of unspecified marital status ${ }^{28}$. The variation could be due to the periods of the studies; since the lowest awareness was reported in 2008 and highest awareness in 2016. However, a recent study conducted in 2019, reported low awareness of $47.9 \%$, among street youths in the South-Western region 17. The two studies that only interviewed males also reported low awareness rates of 48.15 and $45.6 \% 0^{14,17}$.

Despite the high levels of awareness among the female respondents, the use of the FC was low and ranged between $0.2 \%$ and $15.9 \%$, with an average of $5.5 \%$ (Fig. 2a). Males also reported low levels of partner use, and an average of $5.05 \%$ (Fig.2b). Use was similar in both studies that interviewed male respondents, which reported use of $5.5 \%$ and $4.6 \%$, respectively ${ }^{14,17}$.

Of the fifteen studies that reported the use of the FC, the 2007 National HIV/AIDS and Reproductive Health Survey (NARHS) reported the lowest use of the FC $(0.4 \%)^{29}$. Seven studies, which were conducted among undergraduate students showed a wide range of frequency of FC use between $1.9 \%$ and $11.3 \%$ in the South-Western region ${ }^{19,21,22}$. A similar pattern was reported from the South-Eastern region where use ranged from $3.0^{\%}$ to $15.9 \%{ }^{23,25,26}$. The trend is not different in the South-South region, with an $8.9 \%$ average $\mathrm{FC}$ use ${ }^{14}$. The percentage is lower among married women $(4.3 \% \& 0.2 \%)$, street youth $(4.3 \%)$ and $0.8 \%$ among men and women of reproductive age ${ }^{17,20,27,30}$. 

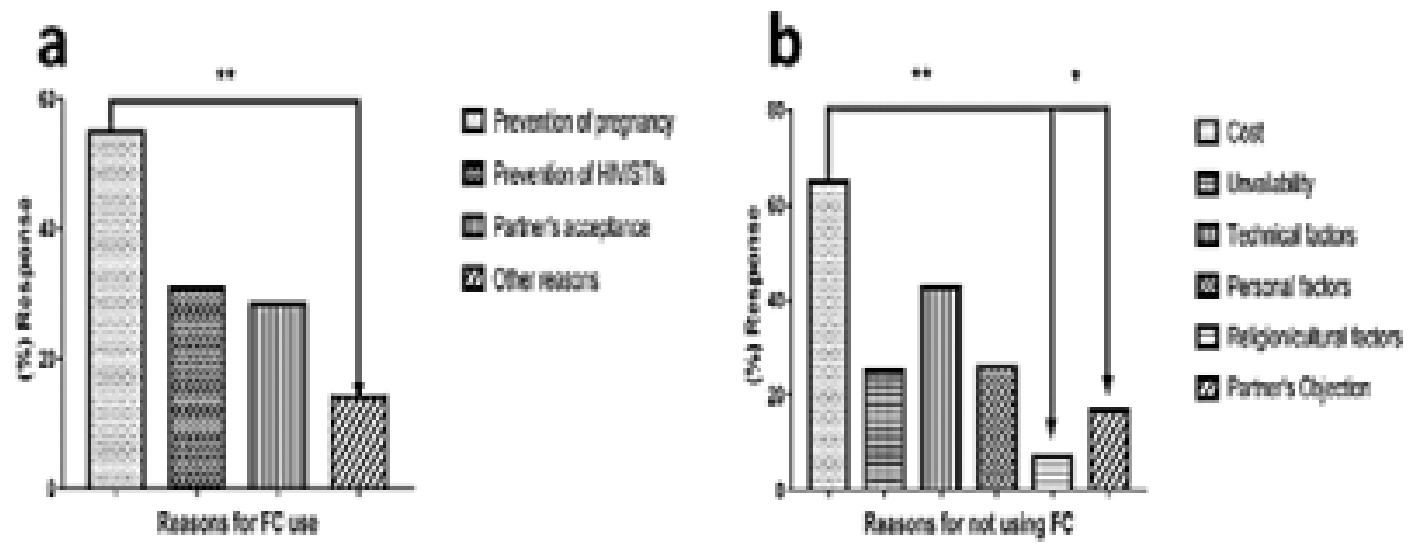

Fig. 3: Reasons for the use and non-use of the female condom.

\section{Reasons for the use and non-use female condom Reasons for the use of the female condom.}

Figure 3 a presents the reasons for FC use by the female respondents., which are categorised into: prevention of pregnancy, prevention of HIV/STIs, partner's acceptance and any other reason/s. One-way ANOVA showed significant differences between the various reasons for FC use among female respondents $[F(3,8)=7.906$, $\mathrm{p}=0.009]$. A significant difference was also noted for using the FC for the prevention of pregnancy versus other reasons for not using the FC $(p<0.006)$. The main reasons for using FC varied among the respondents. While most male respondents cited the prevention of STIs, including HIV as a reason for using the $\mathrm{FC}^{26}$, others cited unwanted pregnancy ${ }^{21}$. Slightly over half of the female respondents $(55 \%)^{14,20,22,31,32}$ used it because they wanted to prevent unwanted pregnancies (Fig. 3a), 31\% used it to prevent STIs, including HIV $21,23,26$ and $28.3 \%$ used it based on their male partner's acceptance ${ }^{14,21,25}$ (Fig. 3a). Some (14\%) used it for other reasons (Fig. 3); such as having sex with a non-regular partner $(22.1 \%)^{25}$ child spacing $(56.9 \%)^{32}$, to meet the sexual needs of the partner irrespective of the woman's menstrual cycle ${ }^{33}$ or for fun $(17.7 \%$ and $28 \%$, respectively) ${ }^{22,23}$. Another interesting reason for using female condoms among female students was that this offered independence as well as a sense of self-empowerment $(19 \%)^{14}$.

\section{Reasons for not using female condoms}

Figure $3 \mathrm{~b}$ presents the reasons for not using the FC by female respondents. One-way ANOVA analysis showed significant differences $[\mathrm{F}(5,13)=5.195, \mathrm{p}=0.0077]$ between the different reasons provided for not using FC by the female respondents. Significant differences were noted between the costs versus religious/cultural factors $(p<0.007)$ and between costs versus personal factors $(p<0.02)$. The reasons for non-use of FC are discussed under the following themes:

Cost and availability: Costs constituted $65 \%$ of the reasons for non-use of FC (Fig. 3b) 14, while the unavailability of FC made up about $25.3 \%$. $^{14,21,25}$.

Technical factors: These included not knowing how to use the FC 25, difficulty in inserting the FC into the vagina, noise during sexual intercourse, its oily nature, the balloon-like looks and failure leading to pregnancy ${ }^{23}$.

Personal factors: The fear of side effects was the most reported reason for non-use; some women believe that contraceptives are harmful to the body ${ }^{27}$, cause decreased sexual satisfaction ${ }^{19}$, pain during sexual intercourse and fear 19,21,23. Many had a low perception of HIV or STI risk and concerns about the length and aesthetic appearance of the condoms were also raised ${ }^{14}$. Female students either did not use it because of male partner objection or preference for other methods of contraception ${ }^{19,25}$.

Religious/cultural factors: One reason for non-use of FC was religious beliefs; some respondents claimed that their religion bans the use of the FC. While others did not use it for cultural reasons, the use of FC was normally seen as taboo in some cultures ${ }^{19,21,25,26}$. 


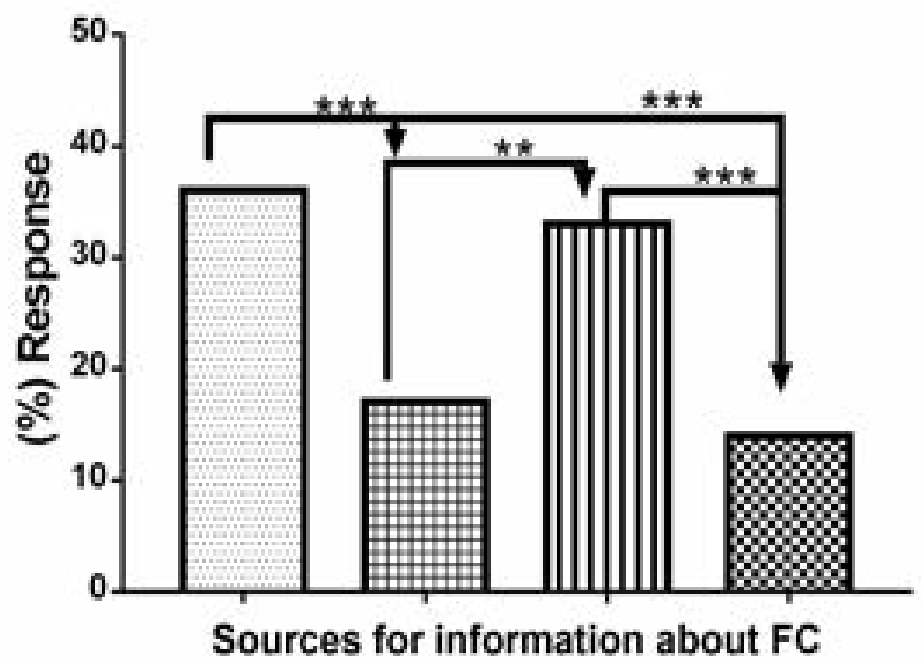

$\square$ Media

田 Family/friends

m Health facilities

A Academic institutions

Fig. 4: Sources of information on the knowledge and use of the female condom.

\section{Sources of knowledge and awareness of the female condom}

Figure 4 presents the sources of information on FC knowledge. One-way ANOVA analyses showed significant differences $[\mathrm{F}(3,8)=32.89, \mathrm{p}<0.0001]$ between the sources of information on FC knowledge. Specific significant differences were also noted between obtaining information from the media versus family and/or friends $(p<0.001)$, media versus academic institutions $(p<0.001)$; health facilities versus family and/or friends $(\mathrm{p}<0.01)$; health facilities versus academic institutions $(p<0.001)$. In Nigeria, the discussion of sex is considered the exclusive preserve of adults ${ }^{34}$. This practice might be responsible for the family contributing a very low percentage, sometimes as low as $0 \%$, as a source of knowledge about contraception and the FC in particular ${ }^{21}$. The media assumes the primary source of information on contraception at $36 \%{ }^{19,25-27,32,35}$, followed closely by health facilities at $33 \%{ }^{22,31,32}$, family and/or friends at $17 \%{ }^{17,23}$ and from academic institutions at $14 \%$.

\section{Discussion}

In this review, we assessed the awareness and use of the FC among Nigerian men and women. Available evidence suggests discordance between awareness and the use of female condoms. Despite high levels of awareness, especially among the female respondents, the use of the FC has remained extremely low, even among the young educated female undergraduate students. The high level of awareness about the FC did not translate to a positive attitude towards its use. A similar study among South African women reported low use among more educated females, which in their case was counteracted by their higher use of the male condom, due to better negotiation skills with the latter ${ }^{36}$. Our results support the findings that correct knowledge of health issues may not always translate into appropriate preventive health actions.

Nevertheless, this review highlighted significant challenges related to FC availability, affordability, ease of insertion, noise during sexual intercourse, its oily nature, the balloon-like looks and failure leading to pregnancy. Other challenges mentioned included the fear of side effects, decreased sexual satisfaction, pain during insertion and during sexual intercourse, the length and aesthetic appearance of the condoms, partner disapproval, preference for other methods of contraception, religious and cultural believes. These could be responsible for its unpopularity among university students. Some studies have also documented similar challenges, in developed countries ${ }^{14,36-38}$. Despite these challenges, however, there were indications of considerable prospects for acceptability and use of female condoms among the students interviewed, as over two-thirds expressed optimism and willingness to try out the condoms if offered as a trial or made available and will even introduce it to their friends and peers ${ }^{14}$.

The primary reasons given by the respondents for their use of the FC are fear of pregnancy (55\%), STIs (31\%) and other reasons (14\%). Female condoms are significant in the quest for a sustainable approach in the prevention of HIV and other STIs and unintended pregnancies ${ }^{8}$. Studies have shown that condoms provide an impermeable barrier to particles the size of sperm and STI pathogens, including HIV ${ }^{39,40}$. The use of condoms, consistently and correctly, is highly effective in pre- venting the sexual transmission of HIV. To ensure 
safe and effective use, FCs must be produced according to specifications, international standards, and quality assurance procedures established by $\mathrm{WHO}^{41}$. Adequate investment in and further scale-up of condom promotion is required to sustain responses to HIV, other STIs, and unintended pregnancy. There is a need for a robust and consistent advocacy to make the FC available either free or at an affordable cost. Moreover, there is a need to intensify awareness to erase erroneous perceptions of the FC, using the media and health facilities, which constituted $36 \%$ and $33 \%$ of the significant sources of information, respectively. Notably, in recent times, social media has played a leading role as an avenue for disseminating reproductive health information amongst youth. Interpersonal communication activities, such as rallies, roadshows, one-on-one educational contacts, group meetings in strategic places like markets, religious houses, schools, and seminars should be encouraged. However, the FC is not an all-or- nothing option, but it should augment the protective options available, there by increasing the choices available to wome ${ }^{36}$.

The limitations of this review include paucity of data on FC from the Northern regions of the country and general lack of data on male's perspectives of FC. This can be overcome through a comprehensive national study on FC to include both genders.

\section{Conclusion}

We conclude that despite the high levels of awareness, especially among the female respondents, the use of the FC has remained extremely low. Therefore, there is the need for deliberate and vigorous advocacy to increase FC demand and increase its availability and af- fordability. There is also a need to erase the erroneous perceptions associated with the female condom.

\section{Acknowledgements}

We would like to thank Mr Rivesh Maharajh for his general technical support.

\section{Authors' contributions}

PDS screened the search output for eligible studies, PDS and FH reviewed the full text of potentially eligible studies for inclusion, extracted data, assessed the risk of bias, and conducted the analysis. PDS prepared the draft manuscript and all authors contributed important intellectual content, read and approved the final version of the review before submission.

\section{Funding}

The Durban University of Technology postdoctoral fellowship grant funds this study. The funders of the study had no role in study design, data collection, data analysis, data interpretation or writing of the report. The corresponding author had full access to all the data in the study and had the final responsibility for the decision to submit the manuscript for publication.

\section{Availability of data and materials}

The datasets analysed during the current study are publicly available and were obtained by searching Google Scholar and PubMed.

\section{Ethics approval and consent to participate}

Not applicable.

\section{Consent for publication}

Not applicable.

\section{Competing interests}

The authors declare that they have no competing interests.

\section{References}

1. United Nations DoE, Social Affairs PD. Contraceptive Use by Method 2019: Data Booklet (ST/ESA/SER. A/435). In: United Nations, Department of Economic and Social Affairs, Population Division; 2019.

2. Hers. The Birth Control Pill vs. Condoms: Which is More Effective? . Hers. 2020.

3. Adachi A, Gendelman HE, Koenig S, et al. Production of acquired immunodeficiency syndrome-associated retrovirus in human and nonhuman cells transfected with an infectious molecular clone. Journal of Virology. 1986;59(2):284-291.

4. HIV/AIDS JUNPo. 2008 report on the global AIDS epidemic. Unaids; 2008.

5. UNAIDS. New survey results indicate that Nigeria has an HIV prevalence of $1.4 \%$. wwwusaids/resources/presscentre/march/20190314 nigeria. 2019.

6. Ayo Adebowale Stephen MTAFFaOJ. Statistical modeling of social risk factor for sexually transmitted diseases among female youths in Nigeria. Department of epidemiology, medical statistics and environmental health, college of medicine, University of Ibadan. 2013. 7. Ananga MK, Kugbey N, Akporlu JM, Asante KO. Knowledge, acceptance and utilisation of the female condom among women of reproductive age in Ghana. Contraception and Reproductive Medicine. 2017;2(1):15.

8. UNFPA W. UNAIDS. Position statement on condoms and the prevention of HIV, other sexually transmitted infections and unintended pregnancy. 2015. In:2016. 
9. Hoffman S, Mantell J, Exner T, Stein Z. The future of the female condom. International Family Planning Perspectives. 2004;30(3):139-145.

10. Abuja N. National Population Commission and ICF Macro; 2009. National Population Commission (NPC) [Nigeria] and ICF Macro Nigeria Demographic and Health Survey. 2008.

11. Koster W, Bruinderink MG, Janssens W. Empowering women or pleasing men? Analyzing male views on female condom use in Zimbabwe, Nigeria and Cameroon. International Perspectives on Sexual and Reproductive Health. 2015;41(3):126-135.

12. Onayade A, Abiona T, Ugbala C, Alozie G, Adetuyi $\mathrm{O}$. Determinants of consistent condom use among adolescents and young adults attending a tertiary educational institution in Ile-Ife, Nigeria. The Nigerian Postgraduate Medical Journal. 2008;15(3):185-191.

13. Hong Y, Li X. HIV/AIDS behavioral interventions in China: a literature review and recommendation for future research. AIDS and Behavior. 2009;13(3):603-613. 14. Tobin-West CI, Maduka O, Onyekwere VN, Tella AO. Awareness, acceptability, and use of female condoms among university students in Nigeria: implications for STI/HIV prevention. International Journal of Adolescent Medicine and Health. 2014;26(2):259-265.

15. Regassa N, Kedir S. Attitudes and practices on HIV preventions among students of higher education institutions in Ethiopia: the case of Addis Ababa University. Educ Res. 2011;2:828-840.

16. Othero D, Aduma P, Opil C. Knowledge, attitudes and sexual practices of university students for advancing peer HIV education. East African Medical Journal. 2009;86(1).

17. Uchendu OC, Adeyera O, Owoaje ET. Awareness and utilization of female condoms among street youths in Ibadan, an urban setting in South-West Nigeria. The Pan African Medical Journal. 2019;33.

18. Moher D, Liberati A, Tetzlaff J, Altman DG. Preferred reporting items for systematic reviews and meta-analyses: the PRISMA statement. Annals of Internal Medicine. 2009;151(4):264-269.

19. Olugbenga-Bello AI, Adekanle DA, Ojofeitimi EO, Adeomi AA. Barrier contraception among adolescents and young adults in a tertiary institution in Southwestern Nigeria: a cross-sectional descriptive study. International Journal of Adolescent Medicine and Health. 2010;22(2):321330.

20. Abalaka G. Married Women's knowledge of and Intention to use female condom in Ibadan South-West local government area, Oyo state, Nigeria 2008.

21. Oladeinde $\mathrm{BH}$, Omoregie R, Abdulfatai A. Aware- ness and use of female condoms among young Nigerian women. CPJ. 2011;2011183:17208.

22. Okunlola M, Morhason-Bello I, Owonikoko K, Adekunle A. Female condom awareness, use and concerns among Nigerian female undergraduates. Journal of Obstetrics and Gynaecology. 2006;26(4):353-356.

23. Ikeako L, Ezegwui H, Mba S, Iyioke C, Okeke T. Prevalence and Factors Associated with Use of the Female Condom among Undergraduates in a University in Enugu, South East Nigeria. Journal of Advances in Medicine and Medical Research. 2015:532-540.

24. Ibe Sally N, Nwoke E, Emerole C, Onyeocha F, Nwawume I, Nwaokoro JC. Knowledge, attitude and perception of road transport workers to HIV/AIDS, STIs and condom use in southeast, Nigeria. Technology. 2014;1(2):50-54.

25. Adinma J, Adinma E, Eke N, Umeononihu O. Condom-Use by Students in a Higher Educational Institution in South Eastern Nigeria. J Comm Pub Health Nurs. 2016;2(127):2.

26. Nwaokoro J, Ede A, Ibe Sally N, et al. Knowledge, attitude and practice of female condom use among undergraduates of the three selected higher institutions in Owerri, South-Eastern Nigeria. Glob Adv Res J. 2015;4(3):132-142.

27. Ajayi AI, Adeniyi OV, Akpan W. Use of traditional and modern contraceptives among childbearing women: findings from a mixed methods study in two southwestern Nigerian states. BMC Public Health. 2018;18(1):604.

28. Asekun-Olarinmoye E, Adebimpe W, Bamidele J, Odu O, Asekun-Olarinmoye I, Ojofeitimi E. Barriers to use of modern contraceptives among women in an inner city area of Osogbo metropolis, Osun state, Nigeria. International Journal of Women's Health. 2013;5:647. 29. Salawu M, Adeyemi A. P3. 329 Awareness and Predictors of Use of Female Condom in the Prevention of Sexually Transmitted Infections in Nigeria. Sex Transm Infect. 2013;89(Suppl 1):A252-A252.

30. Ijarotimi AO, Bakare B, Badejoko OO, et al. Contraceptive uptake among women attending family planning clinic in a Nigerian tertiary health facility: a 6 year review. International Journal of Reproduction, Contraception, Obstetrics and Gynecology. 2017;4(3):722.

31. Usman SO, Kalejaye OO, Isola IN, Oluwaniyi O, Ojogbede AK, Adu AS. Family planning practices among rural community women in Nigeria. J Exp Integr Med. 2016;6(2):88-92.

32. Adeyemi AS, Adekanle DA. Factors influencing the choice of contraceptives among the married women in Osogbo, Western Nigeria. Niger Med Pract. 2009;55(4):59. 
33. Ezire O, Oluigbo O, Archibong V, Ifeanyi O, Anyanti J. Barriers to repeated use of female condom among women and men of reproductive age in Nigeria. Journal of AIDS and HIV Research. 2013;5(6):206-213.

34. JI BD A, Agbai A, Okeke A. Sexual behavior and pregnancy among Nigerian students. Advances in Contraception. 1994;10(4):265-270.

35. Ezugwu EC, Nkwo PO, Agu PU, Ugwu EO, Asogwa AO. Contraceptive use among HIV-positive women in Enugu, southeast Nigeria. International Journal of Gynecology \& Obstetrics. 2014;126(1):14-17.

36. Haffejee F, Maharajh R. Addressing Female Condom Use among Women in South Africa: A Review of the Literature. International Journal of Sexual Health. 2019;31(3):297-307.

37. Gollub EL. The female condom: tool for women's empowerment. American Journal of Public Health. 2000;90(9):1377.
38. Exner TM, Mantell JE, Hoffman S, Adams-Skinner J, Stein ZA, Leu C-S. Project REACH: a provider-delivered dual protection intervention for women using family planning services in New York City. AIDS Care. 2011;23(4):467-475.

39. Henry DH, Beall GN, Benson CA, et al. Recombinant human erythropoietin in the treatment of anemia associated with human immunodeficiency virus (HIV) infection and zidovudine therapy: overview of four clinical trials. Annals of Internal Medicine. 1992;117(9):739748.

40. WHO U. AIDS epidemic update: December 2001. Geneva: Joint United Nations Programme on HIV. AIDS. 2001.

41. Stover J, Hallett TB, Wu Z, et al. How can we get close to zero? The potential contribution of biomedical prevention and the investment framework towards an effective response to HIV. PLoS One. 2014;9(11). 